\title{
Transtorno de ansiedade social como fator de risco para depressão
}

Stein M.B., Fuetsch M., Muller N.M., Lib R., Wittchen H. Social anxiety disorder and the risk of depression. Arch Gen Psychiatry 58: 251-6, 2001

Comentado por Mariangela Gentil Savoia ${ }^{1}$

\section{Recebido: 19/5/2003 Aceito:5/6/2003}

Os autores se propõem a estudar a relação entre ansiedade social e depressão, hipotetizando que o transtorno de ansiedade social antecede os transtornos depressivos. Tendo em vista que o transtorno de ansiedade social tem a sua primeira manifestação na adolescência, os autores averiguaram essa hipótese em uma amostra de 3.021 adolescentes e adultos jovens (14 a 24 anos). Os dados foram coletados como parte de um estudo longitudinal prospectivo em dois momentos, na linha de base e no seguimento. Foi verificado que a ansiedade social em adolescentes e em adultos jovens é um preditor importante não só para a depressão, mas também para a gravidade desta. Uma comparação relevante é que a ansiedade social com início na adolescência tem um impacto mais deletério do que quando ocorre a primeira manifestação da doença após essa fase. Os autores discutem algumas inferências apontadas pela literatura referentes ao papel da esquiva e da ansiedade na contribuição para o isolamento social e conseqüente depressão.
Não é discutido o papel do desenvolvimento de habilidades sociais que costumam ser adquiridas na fase da adolescência, o que talvez explique o porquê de os adultos jovens apresentarem um melhor prognóstico de depressão do que os adolescentes.

A relevância deste trabalho está em tentar esclarecer a ocorrência da co-morbidade entre depressão e ansiedade social, o que é freqüente. Van Ameringen et al., 1991, evidenciaram uma prevalência de $70 \%$ de depressão maior em fóbicos sociais. A indicação de que a gravidade do transtorno depressivo está relacionada com a idade inicial em que se manifesta a ansiedade social pode levar o profissional de saúde a pensar em um trabalho preventivo.

\section{Referência bibliográfica}

Van Ameringen, M.; Mancini, C.; Styan, G.; Donison, D. Relationship of Social Phobia with Other Psychiatrc Illness. J Affect Disord 21: 93-9, 1991.

\footnotetext{
Doutora em Psicologia pela USP. Psicóloga pesquisadora do AMBAN - Instituto de Psiquiatria do HCFMUSP.

Endereço para correspondência:

Instituto e Departamento de Psiquiatria da FMUSP

Rua Dr. Ovídio Pires de Campos s/n, São Paulo, SP - CEP 05403-010
} 